\title{
Pediatric anterior cruciate ligament reconstruction outcomes
}

\author{
Devin C. Peterson ${ }^{1}$ • Olufemi R. Ayeni ${ }^{2}$
}

Published online: 5 October 2016

(C) Springer Science+Business Media New York 2016

\begin{abstract}
Treatment of pediatric anterior cruciate injuries have become an area of controversy sparking much debate about best management strategies. Delaying surgery until skeletal maturity has often been shown to result in unfavorable outcomes due to concomitant meniscal and chondral injuries in this population. There have been numerous techniques used to reconstruct the ACL in the skeletally immature patient; however, most studies are limited by small patient numbers and other methodological concerns. With recent publications reporting failure rates as high as $15-25 \%$ and growth disturbances being uncommon but now reported within almost every technical category, patient and caregiver education become of paramount importance. Key principles will be outlined that may help to avoid some of the pitfalls that occur when dealing with this unique population.
\end{abstract}

Keywords Anterior cruciate ligament - Pediatrics · Physis · Complications

This article is part of the Topical Collection on Outcomes Research in Orthopedics

Devin C. Peterson

dpeters@mcmaster.ca

Olufemi R. Ayeni

femi777@hotmail.com

1 Department of Surgery, McMaster University, 1200 Main Street West, Suite 4E11, Hamilton, ON, Canada

2 Department of Surgery, McMaster University, 1200 Main Street West, Suite 4E15, Hamilton, ON, Canada

\section{Introduction}

There are multiple areas of controversy in sports medicine, and the management of anterior cruciate ligament (ACL) injuries in the skeletally immature patient is one such burgeoning topic. With the potentially increasing numbers of these injuries in children [1], and the delicate balance that exists between the need to stabilize the knee with a reconstruction and the need to avoid growth plate (physeal) injury, an evidence-based approach is crucial.

Delaying ACL reconstruction (ACLR) until skeletal maturity in ACL deficient individuals to avoid injuries to the physis of the distal femur and proximal tibia is one option. However, the natural history of non-operative management in this particular population is poor regarding further intra-articular injury [2-4]. More recent studies have confirmed the unfortunate prognosis of non-operative management in these young individuals. Newman et al. [5] reported on factors contributing to the prevalence and severity of concomitant chondral and meniscal injuries among an older cohort (14 to 19 years old) at the time of ACLR versus those $\leq 14$ years old. They found that a significant relationship exists between time to surgery and the development of an irreparable meniscal injury in both groups and in the severity of chondral injuries in the younger group.

Similarly, Anderson et al. [6] reviewed patients younger than 17 years (median age 14) who underwent ACLR and found that patients that waited for surgery in the subacute (6-12 weeks) and chronic (>3 months) groups had a 1.45 and 2.82 times, respectively, higher odds of lateral meniscal tear severity according to the International Society of Arthroscopy and Knee Surgery and Orthopaedic Sport Medicine (ISAKOS) meniscal classification system. The adjusted odds ratio for increased severity of medial meniscal tears included time to surgery $>3$ months, and the risk factor 
for a chondral injury and for an increased grade of chondral injury also included increased time to surgery $>3$ months.

Mansson et al. [7] reviewed the long-term complications of delayed ACLR in 29 adolescent patients (mean age 15.2 years, range 12-16) whose surgery was delayed until they reached an almost skeletally mature age. Patients had a mean of 11.6 months between their injury and index operation, and time to follow-up was 175 months (range, 106-234). Fiftyfive percent were noted to have meniscal tears at the time of their index operation. Patients were also found to have significantly more degenerative changes in their reconstructed knee than in their contralateral knee, 65 versus $14 \%$, and had revision rate of $14 \%$. Despite the study design limitations, concerning findings of further knee structural damage with delay to treatment was evident.

This concern about further structural damage, combined with the challenges of ensuring compliance in the young patient to modify activity level has led to increasing efforts to safely stabilize the knee in the skeletally immature patient. Consequently, numerous surgical techniques and large numbers of expert opinions on this topic have emerged. There are three broad categories of reconstructive techniques that have been identified:

1. Physeal-sparing ACLR that does not involve drilling across the physis of either the tibia or femur

2. Partial transphyseal ACLR that violates the tibial physis but not the femoral physis

3. Transphyseal ACLR that violates both the tibial and the femoral physis

The objective of this article is to review the current literature regarding outcomes of ACLR in the skeletally immature patient using contemporary surgical approaches and to outline some of the potential pitfalls in treating these individuals.

\section{Anatomy, physiology, and growth of the pediatric knee}

Crucial to the understanding of the skeletally immature athlete is the ability to appreciate the singular differences between these individuals and their skeletally mature counterparts. A major difference is the existence of the physis. The contribution of distal femoral physis and proximal tibial physis to the overall growth of the lower extremity are 37 and $28 \%$, respectively [8]. Some generalizations can be made regarding growth such as the cessation of growth is roughly 14 in girls and 16 in boys and that during the last few years of growth the distal femoral physis contributes to roughly $10 \mathrm{~mm}$ of growth per year and the proximal tibial physis to $6 \mathrm{~mm}$ [8]. It must be kept in mind that not all children follow these rules and each case must be independently and carefully analyzed.
Table 1 outlines research that has been published regarding growth around the pediatric knee, specifically as it relates to the ACL. The relationship between the femoral attachment of the ACL and the adjacent femoral physis has been studied and the top of the femoral attachment has been found to be approximately within $3 \mathrm{~mm}$ of the physis [9]. This presents a challenge during surgery designed to avoid drilling through the physis and even with use of the over-the-top technique.

Studies to determine the growth of the intercondylar notch in the skeletally immature knee may be beneficial in understanding potential risks in this population. Although the femoral intercondylar notch development appears to continue steadily throughout skeletal development until the age of 11 years [10], the femoral notch width index (NWI) (ratio of the intercondylar notch width to bicondylar width) has shown conflicting results as to how it changes with aging [11, 12]. Domzalski et al. [12] also reviewed the relationship of the NWI to the cruciate ligaments. The ACL/notch and PCL/ notch ratios increased with time, which might partly explain the lower prevalence of ACLR in younger children than adolescents who may have proportionally less space for the ACL in the notch.

Similar studies have been conducted on the skeletally immature tibia. Swami et al. [13] reviewed the MRI scans in 570 pediatric knees with open physis. An important finding was that the mean vertical epiphyseal height (difference between the physeal plate and the tibial articular surface) was only $15.9 \mathrm{~mm}$ in the adolescent group (11-15 years) with significant differences between 11 year olds $(15.2 \mathrm{~mm})$ and 15 year olds $(16.6 \mathrm{~mm})$ and between males $(16.6 \mathrm{~mm})$ and females (14.8 mm). Furthermore, the preadolescent group (6-10 years) only had a mean vertical height of $15.1 \mathrm{~mm}$. This has potential implications when considering an all-epiphyseal reconstruction as the safe zone between the tunnel and either the physis or the articular surface is very small.

Increased tibial slope as a risk factor for ACL rupture in adults has been previously reported $[14,15]$, and recent studies have looked at this factor in the pediatric population with mixed results. O'Malley et al. [16] observed the relationship between posterior tibial slope (medial tibial plateau) and ACL rupture in skeletally immature patients versus controls and found a significant difference between the groups, with the ACL injured group having a higher tibial slope. Although a recent MRI study was not able to reproduce this result based on the medial tibial slope (MTS), they did show that an increased lateral tibial slope (LTS) correlated positively with ACL injuries [17]. These investigators also found that the MTS and LTS both decreased by $0.31^{\circ}$ per year as adolescents age. More studies are required to understand the importance of tibial slope as a risk factor for ACL injuries in children and the differences between cartilaginous and bony slope measurements. 
Table 1 Growth of the pediatric knee

\begin{tabular}{|c|c|c|}
\hline $\begin{array}{l}\text { Growth anatomy reviewed } \\
\text { (reference number, year of study) }\end{array}$ & Study characteristics & Findings \\
\hline \multicolumn{3}{|l|}{ Femur } \\
\hline $\begin{array}{l}\text { Relationship between top of ACL } \\
\text { and physis }(9,2001)\end{array}$ & $\begin{array}{l}\text { MRI study on } 13 \text { SI knees } \\
\text { aged 5-15 years }\end{array}$ & $\begin{array}{l}\text { No significant change with growth: mean } \\
\text { distance of } 2.92 \mathrm{~mm} \\
\text { OTT position immediately adjacent to physis }\end{array}$ \\
\hline $\begin{array}{l}\text { Intercondylar notch development } \\
\quad(11,2011)\end{array}$ & $\begin{array}{l}\text { MRI study on } 132 \text { SI knees } \\
\text { aged } 4-18 \text { years }\end{array}$ & $\begin{array}{l}\text { Osseous NWI increased with maturity } \\
\text { Cartilagenous NWI constant regardless of age } \\
\text { Reviewed normal graft width and length }\end{array}$ \\
\hline $\begin{array}{l}\text { Intercondylar notch development } \\
\quad(12,2015)\end{array}$ & $\begin{array}{l}\text { MRI study on } 76 \text { SI patients } \\
\text { aged } 3.8-16.9 \text { years }\end{array}$ & $\begin{array}{l}\text { NWI decreased with age } \\
\text { ACL/knee and PCL/knee ratios similar over time } \\
\text { ACL/notch and PCL/notch ratios increased }\end{array}$ \\
\hline \multicolumn{3}{|l|}{ Tibia } \\
\hline $\begin{array}{l}\text { Relationship between the tibial } \\
\text { ACL and epiphysis }(13,2014)\end{array}$ & $\begin{array}{l}\text { MRI study on } 570 \text { SI patients } \\
\text { aged } 6-15 \text { years }\end{array}$ & $\begin{array}{l}\text { Percentage of the AP tibial diameter for anterior } \\
\text { position of ACL increased with age, posterior } \\
\text { trended to slightly decrease, center remained } \\
\text { constant (mean } 51.5 \% \text { in the } 11-15 \text { years group) } \\
\text { Mean vertical epiphyseal height went from a } \\
\text { mean of } 15.1 \mathrm{~mm} \text { in the youngest group } \\
\text { (6-10 years) to } 15.9 \mathrm{~mm} \text { in the oldest } \\
\text { group (11-15 years) }\end{array}$ \\
\hline Tibial slope $(16,2015)$ & $\begin{array}{l}\text { Radiographic study comparing SI } \\
\text { patients with ACL tears (aged 9-17 years) } \\
\text { with an aged matched control group } \\
\text { (aged 9-16 years) }\end{array}$ & $\begin{array}{l}\text { Posterior slope as measured by the medial tibial } \\
\text { plateau was significantly different between } \\
\text { the ACL injured (mean } 10.0^{\circ} \text { ) and the controls } \\
\left(\text { mean } 8.5^{\circ}\right)\end{array}$ \\
\hline Tibial slope $(17,2015)$ & $\begin{array}{l}\text { MRI study comparing } 76 \text { SI patients } \\
\text { with ACL tears (aged 12-17) with an } \\
\text { age and sex-matched control group } \\
\text { (aged } 12-17 \text { years) }\end{array}$ & $\begin{array}{l}\text { Posterior slope was measure using the articular } \\
\text { surface of both the medial and lateral plateaus } \\
\text { MTS did not correlate with ACL injury but LTS did } \\
\text { LTS had a cut off value of }>4^{\circ} \text { resulting in a sensitivity } \\
\text { and specificity of } 76 \text { and } 75 \% \text {, respectively }\end{array}$ \\
\hline
\end{tabular}

SI skeletally immature, OTT over-the top position, NWI notch width index (ratio of the intercondylar notch width to bicondylar width), AP anteroposterior, MTS medial tibial slope, LTS lateral tibial slope

Christino et al. [18] performed a retrospective review of adolescent patients (mean age 15.8 years) who underwent computer-assisted transphyseal single bundle ACLR. Adolescent patients had significantly higher internal rotation than adults both before and after their ACLR. Adolescents were also noted to have a higher average percent correction of anterior translation compared to the percent of rotational correction. Greenberg et al. [19] reviewed patients that underwent all-epiphyseal hamstring ACLR by assessing their limb symmetry index (LSI), a measure of strength recovery and functional performance. Comparing the LSI of the operated and non-operated limbs for isokinetic data and functional hop scores revealed that only $25 \%$ of subjects were able to achieve an LSI of $\geq 90 \%$ on all testing parameters at a mean of 15 months post-surgery. They also found that quadriceps strength symmetry was more difficult to restore than the hamstring symmetry. They concluded that some pediatric patients may have significant deficits for more than a year after ACLR and may benefit from a more prolonged rehabilitation program.

\section{Outcomes of ACLR techniques in the skeletally immature patient}

There have been a large number of studies reviewing the outcomes of ACLR in this special population. Many of these studies suffer from small sample size, use of chronologic rather than bone age, and poor reporting of outcomes. Although a validated ACL specific outcome score for this age group does not exist, the pedi-IKDC (The International Knee Documentation Committee) has been found to have acceptable psychometric performance for outcome assessment of children and adolescents with various knee problems, including ACL injuries [20]. Unfortunately, this outcome score has yet to become commonplace. Interpretation of outcome scores that are validated only for adults must be assessed cautiously in the pediatric literature.

The following sections outline many of the studies that have been published over the last 3 years on ACLR in the skeletally immature patient. It is beyond the scope of this article to review all of the known techniques that have been 
described for ACLR in skeletally immature patients. Table 2 includes the demographic data of the included studies.

\section{Physeal-sparing ACLR}

Nawabi et al. [21] performed ACLR in patients with a bone age at the time of surgery of 13.6 years. Their anatomic technique involved an autologous quadrupled hamstring graft (minimum $8.5 \mathrm{~mm}$ diameter) fixed with a reverse-tensioning button on the femoral side and an attachable button system on the tibial side. They used MRI and full-length standing radiographs to assess graft survival, growth arrest, physeal violation, angular deformity, and leg length discrepancy. Minimal total tibial physeal violation was observed (mean $2.1 \%$ ) and there were no cases of significant growth issues, although one patient had a 14-mm difference in their leg length postoperatively compared to $3 \mathrm{~mm}$ pre-operatively. This prospective study had a number of limitations including a small sample size, short follow-up, loss of data on the periphery of the sagittal MRI slices, and no assessment of failures or return to pre-operative level of sport.

Koizumi et al. [22] retrospectively evaluated their data base for clinical outcomes of ACLR using a double bundle physeal-sparing technique with hamstring autograft. They used an anatomic tunnel position for both the tibial and femoral postero-lateral bundle positions and for the antero-medial bundle of the tibia. The antero-medial bundle of the femur was placed in a non-anatomic over-the-top position. Median age was 14 years at the time of the index surgery and clinical outcomes included manual Lachman test, pivot-shift test, KT-2000 arthrometer, IKDC score, and the Lysholm Knee Scoring Scale. Comparison was made to a cohort of adult patients who also underwent a double bundle ACLR. There were no statistically significant differences between the groups in any of the outcome measures; however, the rupture rate of the grafts was $13.3 \%$ in the skeletally immature group compared to $7.5 \%$ in the adult group. Study limitations include retrospective design, small sample size, heterogeneity of the surgical procedure (six intra-epiphyseal tibial techniques, nine transphyseal tibial techniques), short-term follow-up, non-anatomic femoral fixation, and no assessment of return to pre-operative level of sport.

\section{Partial transphyseal ACLR}

Demange et al. [23] reviewed their long-term results of nonanatomic partial transphyseal ACLR with double-stranded semitendinosus grafts in patients with an average age of 10.7 years, using transphyseal tibial tunnel drilling and overthe-top femoral fixation. Clinical outcomes included Lachman test, pivot-shift test, return to sports activity, and IKDC. They reported that $83 \%$ had a grade A IKDC score at the end of growth and no patient had any growth disturbances; however, they reported a graft rupture rate of $25 \%$. Study limitations include small sample size, non-anatomic femoral fixation, and descriptive rather than numerical terminology for growth plate pathology.

Cassard et al. [24] retrospectively reviewed patients with a mean age of 13 years who underwent ACLR with a four strand semitendinosus tendon implanted into intraepiphyseal retro-reamed sockets. The surgical technique involved an all-epiphyseal femoral socket and a small tunnel $(4.5 \mathrm{~mm})$ across the tibial physis combined with a larger intra-epiphyseal recess for the graft. Outcomes included laxity, growth disturbance, secondary lesions, and Lysholm and Tegner scores. None of the patients reported meniscal symptoms or degenerative changes, and there were no knees that had laxity greater than $2 \mathrm{~mm}$. Patients reportedly returned to a previous or higher level of activity, and the mean Tegner activity score at followup was 8.4 and the Lysholm score was 95.4. Failure rate was $7 \%$ and although they suggested there were no

Table 2 Study demographics

\begin{tabular}{lllllll}
\hline $\begin{array}{l}\text { Type of } \\
\text { study }\end{array}$ & $\begin{array}{l}\text { Author } \\
\text { (reference number) }\end{array}$ & $\begin{array}{l}\text { Year of } \\
\text { publication }\end{array}$ & Country of origin & $\begin{array}{l}\text { Number of } \\
\text { patients }\end{array}$ & $\begin{array}{l}\text { Age of patient } \\
\text { (range) }\end{array}$ & $\begin{array}{l}\text { Follow-up } \\
\text { (range) }\end{array}$ \\
\hline $\begin{array}{l}\text { Physeal } \\
\text { sparing }\end{array}$ & Nawabi [21] & 2014 & USA & 15 & Mn 13.6 years (11-15) & Mn 21 months (12-39) \\
Partial transphyseal & Koizumi [22] & 2013 & Japan & 15 & Md 14 years (13-16) & Md 38 months (25-48) \\
& Demange [23] & 2014 & Brazil & 12 & Mn 10.7 years (8.3-12.4) & Minimum 15 years \\
& Cassard [24] & 2014 & France & 28 & Mn 13 years (9-15) & Mn 2.8 years (2-5) \\
Transphyseal & Nawabi [21] & 2014 & USA & 8 & Mn 14.5 years (13.5-16) & Mn 14 months (12-18) \\
& Calvo [25] & 2015 & Chile & 27 & Mn 13 years (12-16) & Mn 10.6 years (10-13) \\
& Kohl [26] & 2013 & Switzerland & 15 & Mn 12.8 (6.2-15.8) & Mn 4.1 years (1.9-9.7) \\
& Schmale [27] & 2014 & USA & 29 & Mn 14 years & Mn 4 years (2-8) \\
\hline
\end{tabular}

$M n$ mean, $M d$ median 
growth abnormalities, they do note that the maximum LLD was $1 \mathrm{~cm}$ in nine of their patients and the hipknee-ankle angle was $3^{\circ}$ different than contralateral side in five. Study limitations include small sample size, shortterm follow-up, the absence of a pre-operative outcome scores, heterogeneity of the surgical technique, and lack of specific information on sporting activity.

Nawabi et al. [21] also reviewed their patients who underwent anatomic partial physeal ACLR who had a bone age of 14.5 years and had an all-epiphyseal femur and transphyseal tibia. The total tibial physeal violation was $5.4 \%$ and despite the all-epiphyseal technique there was one patient with a $1.5 \%$ compromise of their total femoral physis. There were no cases of significant growth issues. Limitations of this study have been commented on above.

\section{Transphyseal ACLR}

Calvo et al. [25] performed a long-term retrospective follow-up of their database on the functional outcomes and secondary complications of transphyseal intra-articular ACLR with hamstring graft and vertically oriented tunnels in patients with an average age at surgery of 13 years. Clinical outcomes included Tegner, Lysholm, and IKDC subjective scores, laxity, return to sport information, failure rates, growth arrests, and degenerative findings. Outcome scores were significantly improved post-operatively and all patients were able to return to their previous sports activity with the exception of $11 \%$ moving to a lower level of competition. There were no growth arrests reported or degenerative changes. Two patients had instability during sport and the mean difference in the KT-1000 arthrometry was 2.58 (range -2.7 to $7 \mathrm{~mm}$ ), with $22.3 \%$ of the patients having $\geq 5 \mathrm{~mm}$ difference. Although the graft rupture rate was described as only three patients (11\%) in the abstract, there was an additional patient who had progressive instability and an absent graft at arthroscopy, therefore, the revision rate was actually $15 \%$. Finally, two patients developed chondral lesions and one had a lateral meniscus tear, all requiring reoperation. Study limitations include retrospective design and small sample size.

Kohl et al. [26] presented their results of transphyseal ACLR using unilateral "soft tissue only" quadriceps tendon grafts in patients with a mean age of 12.8 years. There were no changes to the transphyseal tibial tunnel to account for the open growth plates, the femoral tunnel was drilled transtibially, and the grafts (average size $8.2 \mathrm{~mm}$ ) were fixed by sutures to a screw/washer construct. This prospective study reported on outcome scores (Lysholm-Gillquist, IKDC 2000, SF-12 physical [PCS], and mental component summary [MCS]), radiographic analysis, and rupture rates. They did not report any graft failures, although, only one knee was normal on IKDC 2000 (grade A) and only one had a normal ligament finding on Lysholm-Gillquist scoring. Four of the patients were found to have $>2 \mathrm{~mm}$ side to side difference on post-operative Lachman testing, although none had $>5 \mathrm{~mm}$ difference. They had two patients with a $>10$ $\mathrm{mm}$ leg length discrepancy $(18 \mathrm{~mm}$ and $20 \mathrm{~mm})$ and one borderline $10 \mathrm{~mm}$ discrepancy. Furthermore, they reported a progressive valgus deformity $\left(6^{\circ}\right.$ more than the contralateral side) of the distal femur due to a damaged postero-lateral epiphyseal plate. Limitations include small sample size, lack of pre-operative outcome data, and no assessment of return to pre-operative level of sport.

Schmale et al. [27] performed a retrospective review of patients with a mean age of 14 years who had a transphyseal ACLR using hamstring autograft or tibialis anterior allograft with button fixation on the femur and a screw and post for the tibia. The tibial tunnel was drilled centrally with care taken to avoid the tibial apophysis, and a transtibial femoral drilling was used in a more vertical fashion. Pre-operative and post-operative outcome scores were used and re-operations were reviewed. They reported a graft rupture rate of $14 \%$ and a contralateral ACL rupture rate of $28 \%$. Only $41 \%$ of patients returned to their preinjury level of sport. There were seven minor repeat arthroscopies (e.g., hardware, scar tissue, partial meniscectomy), and there was a significant decrease in activity on Tegner scoring, although, the mean Linkert satisfaction score was high (9, range 4-10) and the mean Lysholm score was 91 (range 61-100). They did not find a clear relationship between function and activity. Limitations include retrospective design, small sample size, lack of the use of full-length X-rays to document growth abnormalities, only the Tegner outcome score being available pre-operatively, and missing data such as the KT1000 unit measurements.

\section{Mixed studies}

Unfortunately, some studies do not separate their outcomes based on whether tunnels cross the growth plate or not. Csintalan et al. [28] performed a retrospective study of their registered cohort of primary ACLR in 232 skeletally immature patients (median age 15.1 years) and retrospectively compared these to 1635 patients with closed physis (mean age 16.6 years). Median follow-up time for the group was 498 days. Patients in the skeletally immature group were fixed by a transphyseal technique in $87.1 \%$ of the cases, extraepiphyseal in $9.9 \%$, and $3 \%$ were unknown. There were no significant differences in cartilage injury, overall meniscal injury and repair, early revision (open physis $-5.2 \%$, closed physis $-3.0 \%$ ) and reoperation rate (open physis-3.4\%, closed physis- $4.8 \%$ ). There were significant differences 
between the cohorts regarding gender and body mass index (BMI) with the skeletally immature group having a higher proportion of male patients (66.8 vs $44.0 \%$, respectively) and weighing less (22.8 vs $25.2 \mathrm{~kg} / \mathrm{m}^{2}$, respectively). The proportion of patients with medial meniscal injury was also significantly higher in the skeletally mature group (34.6 vs $26.7 \%$, respectively). Limitations include retrospective design with important information missing, short follow-up, heterogeneity of surgical technique, patient attrition, and lack of patient-reported outcomes.

\section{Graft types}

Due to the small sample size of many of the studies on ACLR, it is difficult to comment on the best graft for reconstructive surgery in these patients. However, Engelman et al. [29•] performed a retrospective study on adolescent patients (range 11-18 years) who had either an autograft (hamstring) or allograft (anterior tibial, posterior tibial, or peroneal) ACLR. The risk of graft failure was 4.4 times higher in the allograft group. The risk for autograft failure tended to remain constant 24-48 months after initial surgery, whereas, the risk for allograft failure continued to increase over this time period.

Goddard et al. [30] reported on their results of a novel graft technique, using living donor allografts from the parents of their patients. The patients (mean age 13 years, range $8-16$ ) had hamstring allografts (mean graft size $7.2 \mathrm{~mm}$, range 6-8) via a transphyseal single tunnel technique. Unfortunately, the physis were closed in five patients thus limiting the ability to compare groups. An antero-medial portal was used for the femoral tunnel with a modified tibial tunnel made to cross the tibial physis as vertical as possible. Femoral fixation was an interference screw, button, or staple, and tibial fixation was an interference screw and/or staple. Suspensory fixation was used if the surgeon felt it was necessary to avoid screws crossing the physis. Their study included 31 patients at a minimum of 2 years follow-up, and they reviewed IKDC ligament examination and KT-1000 arthrometer. They reported a $6 \%$ graft rupture rate and no cases of limb malalignment. Of those that were able to complete the clinical and subjective review, they found a mean IKDC subjective score of 97 (range 84-100), a mean Lysholm score of 97 (range 79-100), and normal or nearly normal IKDC ligament grade in $97 \%$. They reported that $86 \%$ were regularly participating in very strenuous activities. Ninety-seven percent of the donors reported that they would undergo the same procedure again. Limitations include small sample size, short-term follow-up, and heterogeneity of surgical technique.

\section{Principles}

As noted above, the current literature on ACLR on the skeletal immature patient is limited and best treatment strategies continue to evolve. The varying ages of patients, heterogeneity of procedures, and non-compliance with rehabilitation and activity restriction that is often found in this population make it almost impossible to clearly recommend one procedure over another in every situation. Despite this, the surgeon dealing with this unique population must understand the risks associated with the management of the skeletally immature patient with an ACL injury and ways to potentially decrease these risks while optimizing patient outcomes. Below are five evidence-based principles that may help to avoid some of the pitfalls that occur when dealing with this population.

Principle \# 1: Delaying surgery until skeletal maturity is often an ineffective strategy Numerous reports [2-6] have outlined the potential for further injury to the knee by delaying surgery after ACL injury in the skeletally immature patient. Although growth arrest is a concern and more problematic in the youngest patients, the long-term consequences of irreparable meniscus or cartilage damage due to an unstable knee are equally concerning.

Principle \# 2: There are no surgeries that completely eliminate the potential for growth disturbances A meta-analysis by Frosch et al. [31] found significant differences in the overall rate of leg length differences or axis deviation being $5.8 \%$ with physeal sparring techniques and $1.9 \%$ with transphyseal techniques. They used a very judicious value of $1 \mathrm{~cm}$ for leg length and greater than $3^{\circ}$ for angular deformity.

Principle \# 3: Modified tunnel drilling may help prevent growth arrest A more vertical position of the tunnels provides less damage to the physis, potentially decreasing growth arrest. Kercher et al. [32] used virtual transphyseal tunnels and determined that a $5 \%$ increased angle decreased the amount of physis removed by $0.2 \%$. Animal studies suggest that damage to a cross-sectional area greater than $7 \%$ of the femoral physis [33] and $4 \%$ of the tibial physis may result in growth arrest [34].

Thermal injury has been suggested as a possible risk factor for physeal injury $[35,36]$. Slower drilling speed (e.g., using a manual drill) should decrease this complication [35].

A medial drilling entry point on the tibial cortex will help avoid damage to the anterior tuberosity and subsequent genu recurvatum [37]. Risk of growth arrest exists in the peripheral portion of the distal physis/perichondrial ring of the femur [38], so a femoral tunnel exiting in this area is likely best avoided. The close relationship between the femoral attachment of the ACL and the adjacent femoral physis demands 
respect for techniques using all-epiphyseal femoral tunnels or the over-the-top technique. [9]

Principle \# 4: Proper graft selection, technique, and fixation are important There are no clear indications for the success of one graft type over another. However, allograft appears to be associated with a higher failure rate in some studies [29•].

Graft size itself has been shown to be important as a potential cause of physeal damage [32, 39] Kercher et al. [32] determined that young patients ( 10 to 15 years old) with tunnels of $8 \mathrm{~mm}$ diameter removed $2.5 \%$ of the distal femoral physis and $2.4 \%$ of the proximal tibial physis, however, a graft diameter of $11 \mathrm{~mm}$ removed up to $7.8 \%$ of the physis. Appropriate sizing should be determined prior to surgery.

Placing bone and hardware across the physis has been shown to cause growth arrest. Kocher et al. [39] surveyed the Herodicus Society and found a number of cases of growth disturbance with associated factors including fixation hardware across the distal femoral physis (three cases) or tibial tubercle apophysis (three cases), as well as bone plugs across the distal femoral physis (three cases). Being closer to skeletal maturity may not be protective against growth arrest caused by foreign material crossing the physis. Two patients in Shifflet et al.'s study [40•] developed tibial recurvatum which may have been related to bio interference screw placement. Both required reconstructive surgery and both were near skeletal maturity according to their bone ages of 14 , one male and one female.

A soft tissue graft that fills the tunnel crossing the growth plate may help prevent closure of the physis (compared to bony grafts across the physis) as shown by Stadelmaier et al. [41]. Nevertheless, a recent study by Shifflett et al. [40•] has re-confirmed the dangers of ACLR even with soft tissue only in the tunnel and in patients very close to skeletal maturity. Two patients (male patient bone age 16 years, female patient bone age 13 years 6 months) developed genu valgum (6.4 and $9^{\circ}$, contralateral valgus $1^{\circ}$ in both cases) following a transphyseal reconstruction with a hamstring autograft despite button fixation on the femur.

"Tenoepipysiodesis" (excessive tensioning of the graft across the physis) may be a potential cause of growth arrest [42]. This may also explain the two cases of growth arrest related to the lateral extra-articular tenodesis in Kocher's article [39]. Unfortunately, the amount of tensioning that causes this complication is currently unknown.

Principle \# 5: Proper patient education is important With recent publications reporting failure rates as high as $15-25 \%$ and growth disturbances being uncommon but reported with all current techniques, patient and caregiver education becomes of paramount importance. The lack of universal guidelines for rehabilitation and return to play combined with potential poor compliance with activity restriction also make this a very challenging group. Close observation and frequent reminders about the importance of safe activities in the early post-operative period are essential.

\section{Future directions}

The need for well-designed studies to confirm the best and safest techniques to reconstruct the ACL in the skeletally immature knee needs to be a priority. Unfortunately, the extreme heterogeneity of this population ( 5 year old vs 16 year old) and surgical techniques limit the ability to make substantial comparisons. Despite this, current research documents that

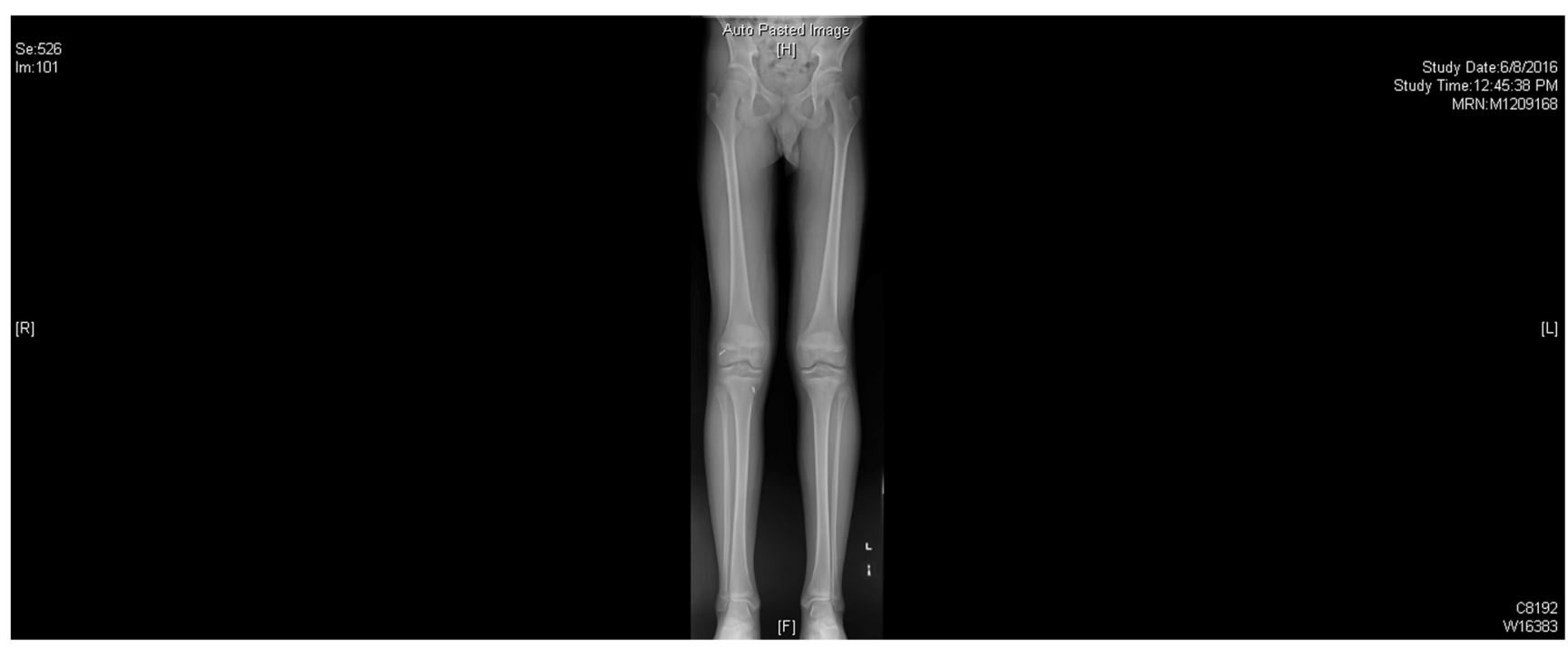

Fig. 1 A standing hip to ankle radiograph and lateral of the knee performed every 3-6 months until skeletal maturity combined with a careful clinical examination provide for reasonable documentation of growth disturbances 
ACLR in this population can be conducted safely when adhering to key surgical principles as outlined above.

Future research needs to include outcome scores focused on this patient population, frequent follow-up until skeletal maturity to assess for growth abnormalities (Fig. 1), and more robust reporting on failure rates of ACLR. Furthermore, age at time of surgery should be reported as skeletal age as there is often a discrepancy between chronological age and bone age.

\section{Conclusion}

The gold standard management for pediatric anterior cruciate injuries has yet to be determined. The heterogeneity of available techniques combined with the lack of good randomized controlled trials comparing these techniques make statements about "best treatment" controversial. The high failure rates now being reported and the potential for physeal injuries creates an environment that can be potentially toxic unless patient education and close follow-up become part of the individualized care of these patients.

\section{Compliance with ethical standards}

Conflict of interest Devin C. Peterson and Olufemi R. Ayeni declare that they have no conflict of interest.

Human and animal rights and informed consent This article does not contain any studies with human or animal subjects performed by any of the authors.

\section{References}

Papers of particular interest, published recently, have been highlighted as:

- Of importance

1. Mall NA, Paletta GA. Pediatric ACL injuries: evaluation and management. Curr Rev MusculoskeletMed. 2013;6:132-40.

2. Henry J, Chotel F, Chouteau J, Fessy MH, Berard J, Moyen B. Ruptureof the anterior cruciate ligament in children: early reconstruction with open physes or delayed reconstruction to skeletal maturity. Knee Surg Sports Traumatol Arthrosc. 2009;17:748-55.

3. Millet PJ, Willis AA, Warren RF. Associated injuries in pediatric and adolescent anterior cruciate ligament tears: does a delay in treatment increase the risk of a meniscal tear? J Arthrosc Relat Surg. 2002;18(9):955-9.

4. Lawrence TR, Argawal N, Ganley TJ. Degeneration of the knee joint in skeletally immature patients with a diagnosis of an anterior cruciate ligament tear. Am J Sports Med. 2011;39(12):2582-7.

5. Newman JT, Carry PM, Terhune EB, Spruiell MD, Heare A, Mayo $\mathrm{M}$, et al. Factors predictive of concomitant injuries among children and adolescents undergoing anterior cruciate ligament surgery. Am J Sports Med. 2014;43(2):282-8.

6. Anderson AF, Anderson CN. Correlation of meniscal and articular cartilage injuries in children and adolescents with timing of anterior cruciate ligament reconstruction. Am J Sports Med. 2014;43(2): 275-80.

7. Mansson O, Sernert N, Rostgard-Christensen L, Kartus J. Long term clinical and radiographic results after delayed anterior cruciate ligament reconstruction in adolescents. Am J Sports Med. 2014;43(1):138-44.

8. Mosley CF. Leg Length Discrepancy. In: Morrissy RT, Weinstein SL, editors. Lovell and Winter's Pediatric Orthopaedics. 5th ed. Philadelphia: Lippincott Wiliams \& Wilkins; 2001. p. 1111-27.

9. Behr CT, Potter HG, Paletta GA. The relationship of the femoral origin of the anterior cruciate ligament and the distal femoral physeal plate in the skeletally immature knee. Am J Sports Med. 2001;29(6):781.

10. Kepler C, Potter H, Green DW, Hammoud S. Intercondylar notch dimensions and growth patterns in young pediatric patients. Presented at the Annual Meeting of the American Academy of Orthopedic Surgeons; 2011 Feb 16-19; San Diego, CA.

11. Edmonds EW, Bathen M, Bastrom TP. Normal parameters of the skeletally immature knee: developmental changes on magnetic resonance imaging. J Pediatr Orthop. 2015;35:712-20.

12. Domzalski ME, Keller MS, Grzelak P, Gabos P. MRI evaluation of the development of the intercondylar notch width in children. Surg Radiol Anat. 2015;37:609-15.

13. Swami VG, Mabee M, Hui C, Jarenko JL. MRI anatomy of the tibial ACL attachment and proximal epiphysis in a large population of skeletally immature knees. Am J Sport Med. 2014.

14. Hashemi J, Chandrashekar N, Mansouri H, et al. Shallow medial tibial plateau and steep medial and lateral tibial slopes: new risk factors for anterior cruciate ligament injuries. Am J Sports Med. 2010;38:54-62.

15. Shelburne KB, Kim HJ, Sterett WI, Pandy MG. Effect of posterior tibial slope on knee biomechanics during functional activity. J Orthop Res. 2011;29:223-31.

16. O'Malley, MP, Milewski MD, Solomitp MJ, Erwteman AS, Nissen CW. The association of tibial slope surgery 2015; 31(1) 7-82.

17. Dare DM, Fabricant PD, McCarthy MM, Rebolledo BJ, Green DW, Cordasco FA, et al. Increased lateral tibial slope is a risk factor for pediatric anterior cruciate ligament injury. Am J Sports Med. 2015;43(7):1632-8.

18. Christino MA, Vopat BG, Waryasz GR, Mayer A, Reinert SE, Shalvoy RM. Adolescent differences in knee stability following computer assisted anterior cruciate ligament reconstruction. Orthop Rev. 2014;6(5653):152-5.

19. Greenberg EM, Greenberg ET, Ganley TJ, Lawrence TR. Strength and functional performance recovery after anterior cruciate ligament reconstruction in preadolescent athletes. Sports Health. 2014: 309-312.

20. Kocher MS, Smith JT, Iversen MD, Brustowicz K, Ogunwole O, Anderson J, Yoo WJ, McFeely ED, Anderson AF, Zurakowski D. Reliability, validity and responsiveness of a modified International Knee Documentation Committee Subjective Knee Form (Pedi-IKDC) in children with knee disorders. 2011; 39(5):933-939.

21. Nawabi DH, Jones KJ, Lurie B, Potter HG, Green DW, Cordasco FA. All-inside, physeal-sparing anterior cruciate ligament reconstruction does not significantly compromise the physis in skeletally immature athletes. Am J Sports Med. 2014; 1-4.

22. Koizumi H, Kimura M, Kamimura T, Keiichi H, Kenji T. The outcomes after anterior cruciate ligament reconstruction in adolescents with open physes. Knee Surg Sports Traumatol Arthrosc. 2013;21:950-6. 
23. Demange MK, Camamho GL. Nonanatomic anterior cruciate ligament reconstruction with double-stranded semitendinosus grafts in children with open physes. Am J Sports Med. 2014.

24. Cassard X, Cavaignac E. aubisson L, Bowen M. Anterior Cruciate ligament reconstruction in children with a quadrupled semitendinosus graft: preliminary results with minimum 2 years follow-up. Pediatr Orthop. 2014;34(1):70-6.

25. Calvo R, Figueroa D, Federico G, Vaisman A, Mococain P, Espinosa M, et al. Transphyseal anterior cruciate ligament reconstruction in patients with open physes. Am J Sports Med. 2014;43(2):289-94.

26. Kohl S et al. Mid-term results of transphyseal anterior cruciate ligament reconstruction in children and adolescents. Knee. 2013. doi:10.1016/j.knee.2013.07.004.

27. Schmale GA, Kweon C, Larson R, Bompadre V. High satisfaction yet decreased activity 4 years after transphyseal ACL reconstruction. Clin Orthop Relat Res. 2014;472:2168-74.

28. Csintalan RP, Inacio MCS, Desmond JL, Funahashi TT. Anterior cruciate ligament reconstruction in patients with open physes: early outcomes. Knee Surg. 2013;26:225-32.

29. Engelman GH, Carry PM, Hitt KG, Polousky JD, Vidal AF. Comparison of allograft versus autograft anterior cruciate ligament reconstruction graft survival in an active adolescent cohort. Am J Sports Med. 2014;42(10):2311-7. Recent study reporting on the high failure rates of allograft use in the adolescent population.

30. Goddard M, Bowman N, Salmon LJ, Waller A, Roe JP, Pinczewski LA. Endoscopic anterior cruciate ligament reconstruction in children using living donor hamstring tendon allografts. Am J Sports Med. 2013;41(3):567-73.

31. Frosch K, Stengel D, Brodhun T, Stietencron I, Holsten D, Jung C, et al. Outcomes and risks of operative treatment of rupture of the anterior cruciate ligament in children and adolescents. J Arthrosc Rel Surg. 2010;26(11):1539-50.

32. Kercher J, Xerogeanes J, Tannenbaum A, Al-Hakim R, Black JC, Zhao J. Anterior cruciate ligament reconstruction in the skeletally immature: anatomical study utilizing 3-dimensional magnetic resonance imaging reconstructions. J Pediatr Orthop. 2009;29(2):124-9.
33. Makela EA, Vainiokpaa S, Vihtonen K, Mero M, Rokkanen P. The effect of trauma to the lower femoral epiphyseal plate: an experimental study in rabbits. J Bone Joint Surg (Br). 1988;70-B:187-91.

34. Guzzanti V, Falciglia F, Gigante A, Fabbriciani C. The effect of intra-articular ACL reconstruction on the growth plate of rabbits. J Bone Joint Surg (Br). 1994;76-B:960-3.

35. Meller R, Kendoff D, Hankemeier S, Jagodzinski M, Grotz M, Knobloch K, et al. Hind limb growth after a transphyseal reconstruction of the anterior cruciate ligament: a study in skeletally immature sheep with wide open physes. AM J Sports Med. 2008;36(12):2437-43.

36. Lawrence TR, West RI, Garrett WE. Growth disturbance following ACL reconstruction with use of an epiphyseal femoral tunnel. J Bone Joint Surg Am. 2011;93(e93):1-6.

37. Shea KG, Belzer J, Apel PJ, Nilsson K, Grimm NL, Pfeiffer RP. Volumetric injury of the physis during single-bundle anterior cruciate ligament reconstruction in children: a 3-dimensional study using magnetic resonance imaging. J Arthrosc Rel Surg. 2009;25(12): 1415-22.

38. Ford LT, Key JA. A study of experimental trauma to the distal femoral epiphysis in rabbits. J Bone Joint Surg. 1956;38-A:84-92.

39. Kocher MS, Saxon HS, Hovis WD, Hawkins RJ. Management and complications of anterior cruciate ligament injuries in skeletally immature patients: survey of the herodicus society and the ACL study group. J Pediatr Orthop. 2002;22:452-7.

40. Shifflett GD, Green DW, Widmann RF, Marx RG. Growth arrest following ACL reconstruction with hamstring autograft in skeletally immature patients: a review of 4 cases. J Pediart Orthop. 2015;00(00):1-6. A very recent article that is one of the first to show significant deformity with soft tissue autograft only crossing the femoral physis and also reporting on significant deformity in patients who were near skeletal maturity at the time of their surgery.

41. Stadelmaier DM, Arnoczky SP, Dodds J, Ross H. The effect of drilling and soft tissue grafting across open growth plates: a histologic study. Am J Sports Med. 1995;23(4):431-5.

42. Houle J, Letts M, Yang J. Effects of a tensioned tendon graft in a bone tunnel across the rabbit physis. Clin Orthop Relat Res. 2001;391:275-81. 